УДК 811.161 .1

ЧЕЛОВЕК В ЗЕРКАЛЕ АССОЦИАТИВНОГО ЭКСПЕРИМЕНТА

(C) Рамзия Болгарова, Эльвира Исламова

\title{
MAN IN THE MIRROR OF ASSOCIATIVE EXPERIMENT
}

\author{
Ramziya Bolgarova, Elvira Islamova
}

Modern linguistics carries out an anthropocentric approach to language, referring to the study of cultural values of representatives of different ethnic groups and to the concepts of the material and inner world of man. The emphasis is shifted from studying the objects of knowledge to its subjects: an individual in language and language in an individual.

The tradition of studying human language consciousness dates back to V. von Humboldt's idea of studying language in close connection with people and their culture. Among the methods of studying language consciousness is an associative experiment, which is a survey of informants, united by a common language, profession, territory of residence, etc. in order to identify their associations to a certain stimulus. These associative experiments are used to create associative dictionaries.

During the research, associative experiments were conducted with 500 students from the city of Kazan - native speakers of the Tatar language. The results were compared with the data from the Russian regional associative dictionary-thesaurus EURAS, posted on the website of the Institute of Linguistics.

The analysis of the associative fields of the lexemes "keshe" in the Tatar language and "man" in the Russian language showed a fairly large percentage of similar strategies in answers, the reactions of respondents revealing the complex contradictory essence of man as a biological, social and psychological phenomenon. However, positive evaluative characteristics and associations, related to moral and ethical components in the meaning of the phrase "to be man", prevail to a greater extent among the speakers of the Tatar language. The reactions of Russian speakers are characterized by a variety of responses, caused by the influence of mass culture, as well as associations with negative connotations and reduced stylistic characteristics.

The associative experiment allows us to reveal the systemic content of the consciousness image behind the word in different languages, and to confirm the uniqueness of the world image in every culture.

Keywords: linguistic consciousness, associative experiment, stimulus, association, reaction, associative field, associative dictionary.

Современное языкознание осуществляет антропоцентрический подход к языку, обращаясь к исследованию культурных ценностей представителей разных этносов, к концептам материального и внутреннего мира человека. Акцент перемещается с исследования объектов познания на субъект, анализируется человек в языке и язык в человеке.

Традиция исследования языкового сознания человека восходит к идее В. фон Гумбольдта об изучении языка в тесной связи с человеком и его культурой. Среди методов изучения языкового сознания выделяется ассоциативный эксперимент, представляющий собой опрос информантов, объединенных общностью языка, профессии, территории проживания и т. д., на предмет выявления их ассоциаций на определенный стимул. Данные ассоциативных экспериментов используются для создания ассоциативных словарей.

В ходе исследования были проведены ассоциативные эксперименты с 500 студентами города Казани - носителями татарского языка. Результаты были сопоставлены с материалами Русского регионального ассоциативного словаря-тезауруса ЕВРАС, размещенными на сайте Института языкознания РАН.

Анализ ассоциативных полей лексем кеше в татарском языке и человек в русском показал достаточно большой процент совпадений в стратегиях ответов, реакции опрошенных раскрывают сложную противоречивую сущность человека как биологического, социального, психологического феномена. Однако у носителей татарского языка в большей степени преобладают положительные оценочные характеристики и ассоциации, связанные с морально-этическими компонентами значения словосочетания «быть человеком». Реакции носителей русского языка отличаются разнообразием ответов, связанных с влиянием массовой культуры, а также ассоциаций с отрицательной коннотацией и сниженной стилистической характеристикой. 
Ассоциативный эксперимент позволяет выявить системность содержания образа сознания, стоящего за словом в разных языках, а также подтверждает уникальность, неповторимость образа мира каждой культуры.

Ключевые слова: языковое сознание, ассоциативный эксперимент, стимул, ассоциация, реакция, ассоциативное поле, ассоциативный словарь.

Характерной чертой современного языкознания является антропоцентризм. Точкой отсчета, центром координат, определяющих предмет, задачи, методы современного языкознания, стал человек. В центре внимания оказывается проблема понимания человеком самого себя.

В. фон Гумбольдт писал о языке как о важнейшем антропологическом факторе: «Человек думает, чувствует и живет только в языке и должен быть вначале сформирован им» [Гумбольдт, c. 77]. Знания и представления о реалиях окружающего мира, многовековой опыт закрепляются в языке и выступают в дальнейшем как ориентир в деятельности общества; «сущность языка состоит в том, чтобы отливать в форму мыслей материю мира вещей и явлений» [Там же, с. 315]. Язык и культура формируют мировидение человека, его восприятие объективной действительности, характер и поведение.

В исследованиях по психолингвистике и когнитивной лингвистике Ю. Н. Караулова, А. А. Залевской, Е. Ф. Тарасова, Н. В. Уфимцевой, И. А. Стернина и др. широко используется термин «языковое сознание». Предметом исследования в целом ряде работ является этнокультурная специфика языкового сознания носителей русской и других культур [Уфимцева, 1998], [Ахметова], [Ашрапова, Шаяхметова, Мухаметзянова].

В татарском языкознании языковое сознание стало объектом исследования сравнительно недавно [Замалетдинов, Габдрахманова, Закирова], [Болгарова, Исламова], [ Габдрахманова, Сибгаева].

Эффективным способом изучения языкового сознания являются экспериментальные методы, в частности методика свободного ассоциативного эксперимента, так как мы можем исследовать сознание только через продукты его деятельности. В ассоциативном эксперименте словостимул вызывает у носителя языка целый ряд ассоциаций, среди которых есть как индивидуальные, связанные с личным опытом, так и присущие группе людей, объединенных общими условиями существования. Реакции носителей языка на слово-стимул образуют ассоциативные поля, на основе которых возможно моделирование определенных фрагментов языкового сознания. Материалы ассоциативных экспериментов становятся базой для создания ассоциативных сло- варей, которые помогают проникнуть в сознание носителей языка [Руль, Гуц, Курулёнок, с. 7475].

Задача нашего исследования - выявить и интерпретировать сходные черты и различия в употреблении и восприятии лексем кеше и человек у татароязычных и русскоязычных студентов через ассоциативный эксперимент. Эксперимент заключается в опросе информантов, объединенных возрастом, профессией, языком и т. п., с целью выявления их ассоциаций на предлагаемые слова-стимулы.

Материалом для нашего исследования послужили результаты свободных ассоциативных экспериментов, проведенных в 2016-2018 годах с 500 студентами Казанского федерального университета и других вузов города Казани в возрасте 17-25 лет, являющимися носителями татарского языка. В экспериментах приняли участие студенты разных специальностей (будущие филологи, ветеринары, энергетики, строители, учителя), гендерный признак представлен в равной степени. В качестве слов-стимулов были отобраны 116 лексем.

В результате анализа полученных материалов выявился ряд лексем, составивших так называемое ядро языкового сознания. На одно из первых мест по числу связей с другими лексическими единицами выходит лексема человек, подобный результат показали исследования целого ряда других языков. Как пишет исследователь В. А. Маслова, «язык как универсальная моделирующая система раскрывает истину о нас самих, нашем сознании и нашем подсознании во всей полноте» [Маслова, с. 5-6]. «Человек»- один из базовых концептов культуры и языка, и это не могло не отразиться на ответах наших испытуемых - молодых, активных, деятельных представителей своего народа. Это и обусловило наш интерес к изучению ассоциативного ряда лексемы кеше в татарском языковом сознании в сопоставлении с русским языком.

Как показали результаты ассоциативных экспериментов, слово-стимул кеше вызвал у опрашиваемых широкий диапазон ассоциаций: из 488 реакций на данный стимул число разных реакций 231 (47,3\%), однако довольно много и единичных реакций - 157 (32,2 \%). Среди самых частотных реакций - синонимичные понятия адәм 'Адам, человек' (27 реакций), зат 'человек' 
(10), инсан 'человек (книжн.)' (2). Человек - это в первую очередь биологическое существо, часть природы, поэтому нередко соотносится с животным, с живым существом: хайван 'животное' (17), ж⿻ан иясе 'живое существо' (6), табигать баласы 'дитя природы' (2), ж⿻әнек 'зверь' (1), маймыл 'обезьяна' (1), организм (1). Причем человек - это, прежде всего, лицо мужского пола, up-am 'мужчина' (4), а потом уже следуют другие ассоциации гендерного плана: әни 'мама' (2), кыз 'девочка, девушка' (2), ана 'мать' (1), әти 'папа' (1), бабай 'дедушка' (1), ир-егет 'мужчина' (1).

Человек наделен разумом, способностью мыслить: акылльь 'умный' (6), акыл 'ум'(2), акыл иясе 'мудрец' (2), уй 'мысль'(2), уйлары 'его (ее) мысли' (1), уйльй ‘думает' (1), гомо сапиенс (1).

Человек - это и социальное существо, все биологическое и психическое в нем социально обусловлено. Человек для современного молодого поколения - это представитель своего народа, член общества: халык 'народ' (8), жсамгыять 'общество' (5), милләт 'нация'(1); он исполняет различные социальные роли, вступает во взаимоотношения с другими людьми: $\partial у с$ 'друг' (10), күрше 'сосед'(3), кунак 'гость'(2).

Отличительным признаком человека являются душа, чувства: ж⿻ан 'душа' (8), ж⿻анлы 'одушевленный, с душой' (2), мәхәббәт 'любовь' (2). Человек - шәхес 'личность' (14).

Носители языка, с одной стороны, очень конкретны в своих ассоциациях: мин 'я' (7), ул 'он, она, оно' (2), без 'мы' (1), алар 'они' (1), син 'ты' (1), с другой - не чужды обобщений: дөнья 'мир, вселенная' (4). Молодежь размышляет, ищет свое место в этом мире, пытается самоопределиться.

Отдельно стоит отметить, что почти всем испытуемым человек представляется скорее хорошим, нежели плохим. Среди оценочных характеристик по шкале «хороший-плохой» явно преобладают положительные: яхшы 'хороший' (24), әйбәт 'хороший' (10), зур 'большой' (8), матур 'красивый' (8), акылль 'умный' (6), бәхетле 'счастливый' (3), намусль 'честный' (3), бөек 'великий' (2), кешелекле 'человечный' (2), көчле 'сильный' (2), сабыр 'терпеливый' (2) и т. д. Отрицательные характеристики расположились в конце ассоциативного ряда: начар 'плохой' (3), усал 'злой' (3), ашәке 'плохой, дурной' (2), явыз 'злой' (2) и т. д. Определенный сдвиг оценок в сторону положительного признака отмечала и Н. В. Уфимцева в ядре языкового сознания русских [Уфимцева, 1998, с. 142].

Материалы проведенных нами ассоциативных экспериментов сопоставлялись с данными
Русского регионального ассоциативного словарятезауруса ЕВРАС, размещенными на сайте Института языкознания РАН. Высокочастотными реакциями носителей русского языка, проживающих на европейской части России, на лексему-стимул человек являются следующие:

«разумный 41 ; паук 31 ; существо 26 ; личность 25 ; животное 22 ; люди 17 ; хороший 14 ; добрый, обезьяна 13 ; я 12 ; умный 11 ; амфибия 10 ; homo sapiens, жизнь 9; красивый 7; друг, закон, индивид 6; мужчина 5; живой, молекула, невидимка 4; глупый, гордо, загадка, закон, общество, разный, разум, родной, слова, терпимый, хомо сапиенс 3; анатомия, волк, года, гордый, гражданин, дела, дитя, дня, дождя, животные, земля, злой, индивидуум, лицо, любимый, молодой, мудрый, муравей, плохой, природа, прямоходящий, развитие, ребенок, сильный, смешной, собака, существа, тупой, уверенный, человек, человеку волк 2» и т. д. [Уфимцева, Черкасова].

Во многом реакции носителей татарского и русского языков совпадают, особенно самые частотные: человек - это биологическое существо: разумный (41); существо (26); животное (22); обезьяна (13); амфибия (10); hoто sapiens (9); разум (3), хомо сапиенс (3); анатомия (2); прямоходящий (2); вершина эволючии (1); Дарвин (1); зверь (1); макака (1); млекопитающее (1); примат (1); человек - социальное существо: закон (3); общество (3); гражданин (2); это личность (25); в гендерном отношении, скорее, это мужчина и т. д. Молодые носители русского и татарского языков проживают в едином культурно-образовательном пространстве, и у них много общего.

Однако носители русского языка чаще дают ассоциации, связанные с влиянием массовой культуры, кино, телевидения, например: паук (31) (ср.: Человек-паук) $и$ закон (6) (телепередача «Человек и закон»); невидимка (4) (Человекневидимка) и т. п. Отмечены интереснейшие реакции, связанные с литературными произведениями: в футляре (1) (рассказ А. П. Чехова «Человек в футляре»); гордо (4); звучит гордо! (1) (пьеса А. М. Горького «На дне»); и пароход (1); пароход (1) (стихотворение В. В. Маяковского «Товарищу Нетте, пароходу и человеку»). В одном из принципов «Морального кодекса строителя коммунизма» утверждалось, что человек человеку - друг, товарищ и брат; среди реакций опрошенных встречаются следующие варианты: человеку волк (2); человеку враг (1); собаке друг (1).

Русскоязычные респонденты более свободны в использовании ассоциатов с отрицательной коннотацией и сниженной стилистической ха- 
рактеристикой: тупой (2); жлоб (1); круто (1); крутой (1) и др.

Среди ответов носителей татарского языка достаточно большое количество ассоциаций связано с морально-этическими ценностями, с традициями народной педагогики как неотъемлемой части духовной культуры народа: кеше булу 'быть человеком' (6); кеше бул 'будь человеком' (3); кеше була бел 'умей быть человеком' (1); кеше булып кал 'оставайся человеком' (1); кеше бульрга 'быть человеком' (1). Эти идеи перекликаются, в частности, с богатейшим паремиологическим материалом татарского языка, со сборником татарских народных пословиц Н. Исанбета: «Әдәм белән әдәм бул!» / 'С человеком будь человеком!' (перевод наш - P. Б., Э. И.) [Исанбет, с. 637]. Справедливости ради нужно отметить, что ассоциации данного типа продиктованы также такими особенностями грамматического строя татарского языка, как постпозиция сказуемого, важная роль составных именных сказуемых.

Итак, в результате массового ассоциативного эксперимента выявляются понятия, наиболее важные для образа мира носителей разных культур, a также знания, определяемые этническими стереотипами поведения носителей той или иной культуры.

Таким образом, ассоциативный эксперимент как один из методов исследования языкового сознания дает возможность исследовать структуру лексикона человека, его языковые предпочтения, ценностные ориентиры. Полученные результаты подтверждают самобытность национальной языковой картины мира.

\section{Список литературы}

Ахметова Л. А. Глагольный способ репрезентации концепта «движение» в языковом сознании носителей немецкого языка (по результатам направленного ассоциативного эксперимента) // Филология и культура. Philology and Culture. 2015. № 4 (42). C. 29-34.

Ашрапова А. Х., Шаяхметова Л. Х., Мухаметзянова Л. Р. Перевод татарских художественных произведений как способ сохранения национального культурного кода (на примере произведений Г. Тукая) // Филология и культура. Philology and Culture. 2016. № 1 (43). C 13-18.

Болгарова Р. М., Исламова Э. А. Цветообозначения в языковом сознании школьников (результаты ассоциативного эксперимента) // Филологические науки. Вопросы теории и практики. Тамбов: Грамота, 2014. № 10 (40). Ч. I. С. 22-26.

Габдрахманова Ф. Х., Сибгаева Ф. Р. Лингвокультурологическое поле Сабантуй в татарской языковой картине мира // Филологические науки. Вопросы тео- рии и практики. Тамбов: Грамота, 2017. № 1 (67). Ч. І. C. $79-81$.

Гумбольдт В. фон. Язык и философия культуры. М.: Прогресс, 1985. 452 с.

Замалетдинов Р. Р., Габдрахманова Ф. Х., Закирова Р. Р. Языковое сознание носителей татарской лингвокультуры (по данным свободного ассоциативного эксперимента). Казань: Отечество, 2016. 172 с.

Исәнбәт H. C. Татар халык мәкальләре ('Татарские народные пословицы'). Казан: Татарстан китап нәшрияты, 2010. Т. 3.799 б.

Маслова В. A. Homo lingualis в культуре: Монография. М.: Гнозис, 2007. $320 \mathrm{c}$.

Руль Н. Н., Гуи Е. Н., Курулёнок А. А. Принципы моделирования ассоциативного поля: лексикографический аспект (на материале ассоциативных экспериментов с респондентами, изучающими русский язык как иностранный) // Филология и культура. Philology and Culture. 2018. № 4 (54). C. 74-80.

Уфимиева Н. В. Этнический характер, образ себя и языковое сознание русских // Языковое сознание: формирование и функционирование. М.: РАН Ин-т языкознания, 1998. С. 135-170.

Уфимиева Н. В., Черкасова Г. А. Русский региональный ассоциативный словарь-тезаурус ЕВРАС // Институт языкознания Российской Академии наук. M., 2014. URL: http://iling-ran.ru/ library/evras/evras_1.pdf (дата обращения: 02.03.2019).

\section{References}

Ahmetova, L. A. (2015). Glagol'nyi sposob reprezentatsii kontsepta "dvizhenie" $v$ iazykovom soznanii nositelei nemetskogo iazyka (po rezul'tatam napravlennogo assotsiativnogo ehksperimenta) [A Verbal Mode of Representing the Concept of Movement in the Linguistic Consciousness of German Language Speakers (based on a directional associative experiment)]. Filologiia i kul'tura. Philology and Culture. No. 4 (42), pp. 29-34. (In Russian)

Ashrapova, A. H., Shayahmetova, L. H., Muhametzyanova, L. R. (2016). Perevod tatarskih hudozhestvennyh proizvedenii kak sposob sohraneniia natsional'nogo kul'turnogo koda (na primere proizvedenii G. Tukaya) [Tatar Fictional Translations as a Method of Preserving the Cultural Code of Nation (based on G. Tukay's Works)]. Filologiia i kul'tura. Philology and Culture. No. 1 (43), pp. 13-18. (In Russian)

Bolgarova, R. M., Islamova, E. A. (2014). Tsvetooboznacheniia $v$ iazykovom soznanii shkol'nikov (rezul'taty assotsiativnogo ehksperimenta) [Colour Terms in the Schoolchildren's Linguistic Consciousness (results of an associative experiment)]. Filologicheskie nauki. Voprosy teorii i praktiki. Tambov, Gramota. No. 10 (40). Ch. I, pp. 22-26. (In Russian)

Gabdrahmanova, F. H., Sibgaeva, F. R. (2017). Lingvokul'turologicheskoe pole Sabantui $v$ tatarskoi iazykovoi kartine mira [Linguistic- Culturalogical Field Sabantuy in the Tatar Language Worldview]. Filologicheskie nauki. Voprosy teorii i praktiki. Tambov, Gramota. No. 1 (67). Ch. I, pp. 79-81. (In Russian) 
Gumbol'dt, V. fon. (1985). Iazyk i filosofiia kul'tury [Language and Philosophy of Culture]. 452 p. Moscow, Progress. (In Russian)

Isənbət, N. S. (2010). Tatar halyk məkal'lare = Tatarskie narodnye poslovitsy [Tatar Folk Proverbs]. Vol. 3. 799 p. Kazan, Tatarstan kitap nəshr. (In Tatar)

Maslova, V. A. (2007). Homo lingualis v kul'ture [Homo Lingualis in Culture]. 320 p. Moscow, Gnozis. (In Russian)

Rul', N. N., Guc, E. N., Kurulyonok, A. A. (2018). Printsipy modelirovaniia assotsiativnogo polia: leksikograficheskii aspekt (na materiale assotsiativnyh ehksperimentov s respondentami, izuchaiushchimi russkii iazyk kak inostrannyi) [Modeling Principles of Associative Fields: A Lexicographic Aspect (Based on a Series of Associative Experiments with the Russian Language Learners)]. Filologiia i kul'tura. Philology and Culture. No. 4 (54), pp. 74-80. (In Russian)

\author{
Исламова Эльвира Альбертовна, \\ кандидат филологических наук, \\ доцент, \\ Казанский федеральный университет, \\ 420008, Россия, Казань, \\ Кремлевская, 18. \\ ea_islamova@mail.ru
}

\section{Болгарова Рамзия Марсовна,} кандидат филологических наук, доцент,

Казанский федеральный университет, 420008, Россия, Казань,

Кремлевская, 18.

ramzija5@yandex.ru
Ufimtseva, N. V. (1998). Etnicheskii harakter, obraz sebia $i$ iazykovoe soznanie russkih [Ethnic Character, the Image of Self, and Linguistic Consciousness of the Russians]. Iazykovoe soznanie: formirovanie i funktsionirovanie. Moscow, RAN In-t iazykoznaniia, pp. 135-170. (In Russian)

Ufimtseva, N. V., Cherkasova, G. A. (2014). Russkii regional'nyi assotsiativnyi slovar'-tezaurus EVRAS [Regional Russian Associative Thesaurus EVRAS]. Institut iazykoznaniia Rossiiskoi Akademii nauk. Moscow. URL: http://iling-ran.ru/library/evras/evras_1.pdf (accessed: 02.03.2019). (In Russian)

Zamaletdinov, R. R., Gabdrahmanova, F. H., Zakirova, R. R. (2016). Iazykovoe soznanie nositelei tatarskoi lingvokul'tury (po dannym svobodnogo assotsiativnogo ehksperimenta) [Linguistic Consciousness of Tatar Speakers' Culture (based on the free associative experiment)]. 172 p. Kazan', Otechestvo. (In Russian)

The article was submitted on 01.04.2019

Поступила в редакцию 01.04.2019

\section{Islamova Elvira Albertovna,}

Ph.D. in Philology,

Associate Professor,

Kazan Federal University,

18 Kremlyovskaya Str.,

Kazan, 420008, Russian Federation.

ea_islamova@mail.ru

\section{Bolgarova Ramziya Marsovna,}

Ph.D. in Philology,

Associate Professor,

Kazan Federal University,

18 Kremlyovskaya Str.,

Kazan, 420008, Russian Federation.

ramzija5@yandex.ru 